\title{
Hereditary pancreatitis in a Newcastle family
}

\author{
J. R. SIBERT \\ From the Newcastle General Hospital, Newcastle upon Tyne
}

\begin{abstract}
Sibert, J. R. (1973). Archives of Disease in Childhood, 48, 618. Hereditary pancreatitis in a Newcastle family. A family with recurrent pancreatitis is described. A 5-year-old girl and her maternal uncle have had pancreatitis diagnosed at laparotomy. Her mother and maternal aunt have had very suggestive histories of recurrent abdominal pain going back to childhood, and during a recent attack the mother was found to have a raised serum amylase. The maternal aunt is a diabetic. In this family, and in the families previously described, an autosomal dominant gene seems to be responsible. Unlike some of the American families, there is no lysine cystine aminoaciduria, though the girl had a slight excess of taurine in her urine.
\end{abstract}

Pancreatitis occurring on a familial basis was first described by Comfort and Steinberg (1952). This appeared to be an autosomal dominant condition with an associated aminoaciduria of lysine and cystine. Gross and his co-workers from the Mayo Clinic described four other kindreds, all with aminoaciduria (Gross and Comfort, 1957; Gross, Ulrich, and Maher, 1962b; Gross, Gambill, and Ulrich, 1962a). Several other families were described by workers in America and in France, establishing the condition as a disease entity (Davidson et al., 1968; Logan, Schlicke, and Manning, 1968; Cornet et al., 1962; Whitten, Feingold, and Eisenklam, 1968.)

Cases of hereditary pancreatitis tend to have an early age of onset, often in childhood without a history of alcohol ingestion (Gross et al., 1962b). A family (Fig.) with a 5-year-old girl, her mother, and her uncle definitely having pancreatitis, and her aunt having a very suggestive history, is reported.

\section{Patients}

Case IV.5. A girl aged 5 years at presentation (May 1972) who had been previously well. She had a 36-hour history of constant central abdominal pain and had vomited four times. There were no bowel or urinary symptoms. On examination she was afebrile, with a pulse of $100 /$ minute and blood pressure of $100 / 70$ mmHg. She had mild central and upper abdominal tenderness without rebound tenderness or guarding. She was not clinically dehydrated. The remainder of the physical examination and urine analysis was negative. It was thought that there was insufficient indication for laparotomy at this stage; however, next morning her abdominal pain had become more severe. On examina-

Received 10 November 1973. tion there was generalized guarding and severe tenderness over the whole abdomen. Her temperature and pulse were unchanged. Laparotomy was performed with a preoperative diagnosis of peritonitis. This was performed through a lower right paramedian incision, and showed clear free fluid with normal appendix and small bowel. The pancreas was thickened and inflamed with considerable induration near the spleen.

After operation she was treated with intravenous fluids and prophylactic antibiotics (ampicillin, erythromycin, and colistin). Though she had a considerable amount of abdominal pain for 4 days after operation, she made a good recovery and was discharged free of pain 9 days after admission. Serum amylase 24 hours after operation was 320 Somogyi units $/ 100 \mathrm{ml}$. She previously had clinical mumps when aged 3 and her mumps $V$ titre was $1 / 40$. This had not risen 2 months later. Serum calcium was $9 \cdot 1 \mathrm{mg} / 100 \mathrm{ml}$. There was no glycosuria and random

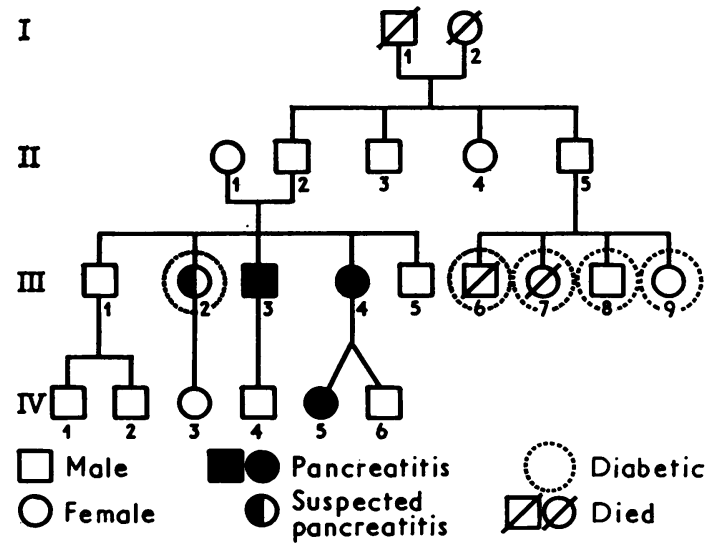

FIG.-Pedigree of affected family. 


\section{Hereditary pancreatitis in a Newcastle family}

blood sugar was $130 \mathrm{mg} / 100 \mathrm{ml}$. Urinary amino acid chromatogram showed an excess of taurine with other amino acids at normal levels. 24-hour taurine excretion (1 month after presentation) was raised at $81 \mathrm{mg} / 24 \mathrm{hr}$. (Normal up to $30 \mathrm{mg} / 24 \mathrm{hr}$ age 3 to 6 years, from Geer, Hantman, and Swett, 1968.) Lipoprotein electrophoresis was normal.

Five weeks after her original presentation she again had severe abdominal pain and vomiting. She had upper abdominal tenderness with variable guarding, but was not shocked nor dehydrated. Serum amylase was 1600 Somogyi units $/ 100 \mathrm{ml}$. Diagnosis of recurrent pancreatitis was made, and she was treated with analgesics (Pethidine) and oral fluids. Her pain resolved over 4 days, she has had no recurrences of her pain since, and remains well 6 months after her original presentation.

Case III.3. Maternal uncle of Case IV.5, born in 1944 and was well until age 17 years. He then started having attacks of severe abdominal pain every 2 to 3 months. These lasted between 2 and 5 days and were associated with vomiting. The pain was epigastric, constant and radiated to the back. His alcohol consumption was no more than 3 to 4 pints of beer per week. When he was aged 19 , he was seen by a physician in outpatients and a provisional diagnosis of peptic ulceration was made, though barium meal was normal.

In May 1964, when he was aged 20, he was admitted to this hospital with an attack of similar severe pain and vomiting. On examination he had generalized abdominal rebound tenderness and guarding, worse in the epigastric region. Serum amylase was 1600 Somogyi units $/ 100 \mathrm{ml}$. At laparotomy the pancreas was found to be hard, inflamed, and grossly nodular. The nodules were isolated lobules. The pancreas was patchy in colour with some nodules being pale and some slightly pink, with a considerable amount of intralobular oedema. The pancreatic duct was not noted to be abnormal. Cholecystectomy and left splanchnicectomy were performed, and a piece of pancreas taken for biopsy. This showed an increase of interlobular fibrous tissue with a small number of mononuclear cells within the vicinity of the ducts. The gall bladder was histologically normal. The postoperative course was complicated by a left basal pneumonia and a pleural effusion; however, this cleared on treatment, and he was discharged 19 days after admission.

Since then he has averaged two to three attacks of abdominal pain per year, only one severe enough to require hospital admission in August 1970. Serum amylase was 560 Somogyi units and calcium $9 \cdot 2 \mathrm{mg} / 100$ $\mathrm{ml}$. Blood sugar was $88 \mathrm{mg} / 100 \mathrm{ml}$. He had one attack at Christmas 1971 associated with a mild alcoholic excess. His stools are normal in appearance. In 1972 there was no abnormal aminoaciduria with 24-hour urine taurine excretion being $71 \mathrm{mg} / 24 \mathrm{hr}$. (Normal for adults up to $95 \mathrm{mg} / 24 \mathrm{hr}$, from Geer et al., 1968.)

Case III.2. Maternal aunt of Case IV.5, born in 1939 and started getting attacks of abdominal pain radiating to the back at the age of 4 years. These were often associated with vomiting and are remembered as being severe. She had two to three attacks per year. In 1947 she had an appendicectomy elsewhere for which no records are available. In 1948, age 9 years, she was admitted to the Royal Victoria Infirmary, Newcastle, with abdominal pain. This was recorded as being central, however no abnormality was noted on examination apart from a slightly raised temperature. Investigations showed white blood count of 11,000 , positive Mantoux, and an old healed primary complex on chest $x$-ray. Urine was normal on microscopy. Her pains subsided after 5 days and she was discharged. She was admitted again in March and September of 1949 with similar pain. Nothing was found on examination and intravenous pyelogram, blood urea, and barium meal were normal. Repeat urine examinations were negative.

Her attacks lessened after this, and since the age of 18 she has had only two severe attacks when aged 29 and 31 , though she has had several minor ones. She developed diabetes mellitus when aged 26, and is now on lente insulin (32 units/day). She has one daughter aged 4 who is well and without abdominal pain, and she is now pregnant again so that straight $x$-ray of abdomen to exclude pancreatic calcification could not be performed. Urine amino acids were within normal limits.

Case III.4. Mother of Case IV.5, aged 25, started having attacks of abdominal pain at the age of 16 . Since then she has had attacks of pain approximately every 6 months. The pain radiates to the middle of the back, and attacks last from 3 to 5 days. She usually vomits with the pain. The attacks of pain have never been severe enough to require hospital admission, though they have been moderately disabling. There is no dysuria or bowel disturbance. The attacks of pain had been diagnosed as pyelitis. Serum amylase (taken when free of pain) was normal (less than 200 Somogyi units/100 $\mathrm{ml}$ ). Intravenous pyelogram was also normal, with no pancreatic calcification. She continues to have attacks, the last being in November 1972, during which a serum amylase of 400 Somogyi units was found. Taurine excretion was normal at $43 \mathrm{mg} / 24 \mathrm{hr}$, with cystine and lysine also within normal limits.

Case IV.6. Twin brother of Case IV.5 is well and has had no pains. Taurine excretion over 24 hours was slightly raised at $47 \mathrm{mg}$, with other amino acids being normal. Serum amylase was normal.

Cases III.1 and III.5. Maternal uncles of Case IV.5, are well and without pain, as are the children of Case III.1 (Cases IV.1 and 2, aged 9 and 4) and the child of Case III.3 (Case IV.4, aged 5).

Case II.2. Maternal grandfather of Case IV.5, aged 64 , has had a past history of acute cholecystitis and myocardial infarction. No comment was made on his pancreas at the time of cholecystectomy, and he has had no pains typical of pancreatitis. There was no calcification on straight $x$-ray of the abdomen, and serum amylase 
was less than 200 Somogyi units. There is no history of abdominal pain in the maternal grandmother (Case II.1), nor in the father of Case IV.5, nor in any of the sibs of Case II.2. However, of some interest is that a younger brother (Case II.5), though well himself, has had 4 children all of whom suffered from diabetes mellitus (Cases III.6-9). Two have died, one aged 2 in probable diabetic coma, the other aged 26 of bronchopneumonia. Atrophy of the pancreas was noted at necropsy. Optic atrophy was noted in Case III.6 and in the two survivors, who are on the blind register. None of these 4 sibs suffered from abdominal pain.

\section{Discussion}

Pancreatitis is a rare cause of abdominal pain in childhood. Perhaps its most common cause is a mumps virus infection; however, another important aetiological factor may be familial pancreatitis. Hendren, Greep, and Patton (1965) described 15 cases of pancreatitis in childhood of which one may have had a familial basis. In the 5 kindreds with hereditary pancreatitis extensively studied at the Mayo Clinic (Gross et al., 1962b), the average age of onset was 11.8 years, and familial pancreatitis comprised $13 \%$ of all cases of pancreatitis seen there. Pancreatitis in a 5-year-old girl (and her mother) was described by Whitten et al. (1968), and in a 14year-old girl (and her father and two uncles) by Nash (1971). Lysine cystine aminoaciduria occurred in all 5 kindreds studied by Gross et al. (1962b); however, this has been reported only in one other family (Carey and Fitzgerald, 1968). It was absent in a large family studied in California by Davidson et al. (1968). Taurine was noted in excess in one patient by Logan et al. (1968), but its significance was doubted, and it is also probably of little significance in this Newcastle family and may be an incidental finding. The Newcastle family seems to fit in with the autosomal dominant pattern of inheritance that has been described in all the other families reported. In many of these families, however, there seems to be a degree of variable penetrance.

The aetiology of familial pancreatitis is in doubt. Cornet et al. (1962) described a French family with 17 members having pancreatitis. In 3 of the 6 patients on whom operation was performed, dilatation of the pancreatic ducts was noted; this was thought to be secondary to an obstructive element. A similar view was taken by Robechek (1967) who described 3 patients with hypertrophy of the sphincter of Oddi found at operation. Spinchterectomy relieved symptoms in 2 of these patients. The pancreatic ducts were not explored in the 2 patients from this Newcastle family on whom laparotomies were performed. The only other published theory is put forward by Adham, Dyce, and Haverback (1968). They found a raised serum trypsin binding activity in some of their patients with familial pancreatitis, and suggested that this might have aetiological significance.

Calcification in the pancreas was noted in 17 out of Gross's 38 patients (Gross et al., 1962b). Diabetes mellitus occurred in many of the families reported and in 9 patients in Gross's series (Gross et al., 1962b). In the family reported here there is one patient with probable pancreatitis and diabetes (Case III.2), and also 4 unfortunate sibs all with severe juvenile onset diabetes (Cases III.6-9). Diabetes is usually quoted as a late complication of pancreatitis associated with extensive fibrosis, and in Gross's series those developing diabetes have had severe pancreatic disease. Though Case III.2 had severe attacks of pain, she developed diabetes in a period of her life when she was relatively free of pain, and there is no evidence that the 4 diabetic sibs ever had pancreatitis. It is possible, therefore, that this family, in addition to familial pancreatitis, has a separate familial tendency to diabetes. Carey and Fitzgerald (1968) described a family with hyperparathyroidism associated with familial pancreatitis; the serum calcium was normal in the patients in this Newcastle family.

There are difficulties in diagnosing pancreatitis outside an acute attack, and it was not thought justified to submit any of the patients to duodenal intubation in order to attempt to confirm the diagnosis. Nevertheless, the history of Case III.2 is very suggestive of recurrent pancreatitis.

In difficult cases of abdominal pain in childhood a serum amylase should be among the investigations considered, just as it is in adults. Moreover, this provides another good reason for looking into the family history in children with abdominal pain.

I thank Dr. Christine Cooper for her help and for permission to publish this case; and Dr. A. Cassells Smith for the biochemical results. I also thank Drs. A. Ashcroft and A. R. R. Cain, Mr. A. H. Petty, Dr. F. Robertson, and Mr. D. Rose for their help; and finally, the members of this family for their kind co-operation.

\section{REFERENCES}

Adham, N. F., Dyce, B., and Haverback, B. J. (1968). Elevated serum trypsin binding activity in patients with hereditary pancreatitis. American fournal of Digestive Diseases, 13, 8 .

Carey, M. C., and Fitzgerald, O. (1968). Hyperparathyroidism associated with chronic pancreatitis in a family. Gut, 9, 700.

Comfort, M. W., and Steinberg, A. G. (1952). Pedigree of a family with hereditary chronic relapsing pancreatitis. Gastroenterology, 21, 54.

Cornet, E., Dupon, H., Hardy, M., and Gordeef, A. (1962). Pancréatite chronique familiale primitive avec ectasies canalaires. Fournal de Chirurgie, 84, 527.

Davidson, P., Costanza, D., Swieconek, J. A., and Harris, J. B. (1968). Hereditary pancreatitis. A kindred without gross aminoaciduria. Annals of Internal Medicine, 68, 88. 
Geer, R. P., Hantman, R. K., and Swett, C. V. (1968). Quantitative chromatographic studies on urinary amino acid excretion. Clinical Chemistry, 14, 12.

Gross, J. B., and Comfort, M. W. (1957). Hereditary pancreatitis. Report on two additional families. Gastroenterology, 32, 829 .

Gross, J. B., Gambill, E. E., and Ulrich, J. A. (1962a). Hereditary pancreatitis. Description of a fifth kindred and summary of clinical features. American fournal of Medicine, 33, 358.

Gross, J. B., Ulrich, J. A., and Maher, F. T. (1962b). Further observations on the hereditary form of pancreatitis. In The Exocrine Pancreas, Normal and Abnormal Functions. CIBA Foundation Symposium, p. 278 . Ed. by A. V. S. DeReuck and M. P. Cameron. Churchill, London.

Hendren, W. H., Greep, J. M., and Patton, A. S. (1965). Pancreatitis in childhood. Experience with fifteen cases. Archives of Disease in Childhood, 40, 132.
Logan, A., Schlicke, C. P., and Manning, G. B. (1968). Familial pancreatitis. American fournal of Surgery, 115, 112.

Nash, F. W. (1971). Familial calcific pancreatitis: an acute episode with massive pleural effusion. Proceedings of the Royal Society of Medicine, 64, 17.

Robechek, P. J. (1967). Hereditary chronic relapsing pancreatitis. A clue to pancreatitis in general ? American fournal of Surgery, 113, 819.

Whitten, D. M., Feingold, M., and Eisenklam, E. J. (1968). Hereditary pancreatitis. American fournal of Diseases of Children, 116, 426.

Correspondence to Dr. J. R. Sibert, Newcastle General Hospital, Westgate Road, Newcastle upon Tyne NE4 6BE. 